\title{
Effect of Virtual Reality During Periodon- tal Treatment of Patients with Anxiety
}

\section{E Birang ${ }^{1}$, J Yaghini ${ }^{2}$, R Birang ${ }^{3}$, M Zohary ${ }^{*}$}

1-Periodontist,Implant fellowship,department of periodontology,school of dentistry,Shahid beheshti medical science university

2- Associated professor,dental implants research center,department of periodontology,school of dentistry,isfahan medical science university

3- Professor of Dental Research Center,Dept.of periodontology,School of Dentistry,Isfahan University of Medical Sciences,Isfahan,Iran.

4-Resident of periodontics, department of periodontology,school of dentistry,Guilan university of medical science

\section{ARTICLE INFO}

Article History

Received: Nov 2018

Accepted: Dec 2018

ePublished: Jan 2019

Corresponding author:

M Zohary, Resident of periodontics, department of periodontology,school of dentistry, Guilan university of medical science

Email:maryamzohary@yahoo.com

\section{ABSTRACT}

Background and Aim:Various methods have been used to reduce the patient's anxiety during dental treatment. In recent years, there has been an increase in behavioral research regarding virtual reality (VR) and virtual world as it offers more immersive images and works by blocking out real-world stimuli (visual, auditory or both). This study aimed at assessing the impact of VR on working conditions and pain during scaling and root planing (SRP) in anxious patients.

Materials and Methods: In this clinical trial, 14 eligible patients were randomly divided into two groups. Participants of one of the groups were wearing eyeglasses during SRP of the first quadrant, while in the other group, SRP was performed without any intervention. The intervention group was reversed for SRP of the second quadrant. The patients' anxiety (dental anxiety scale-revised, DAS-R), pain score (visual analog scale, VAS), blood pressure (BP), and pulse rate (PR) were recorded before and after SRP. Data were analyzed using Mann-Whitney-U test.

Results: There was a significant difference in the patients' PR and stress during SRP between the test and control groups $(\mathrm{P}<0.001)$. Moreover, the patients' anxiety was significantly reduced by using eyeglasses during SRP.

Conclusion: Video eyeglasses are a useful tool for improving the quality of dental care by enhancing the patients' satisfaction and reducing the patients' pain and anxiety.

Keywords:Visual Analog Scale, Dental Anxiety, Virtual Reality

J Res Dent Maxillofac Sci 2019;4(1):9-15.

DOI: $10.29252 / j$ jrdms.4.1.9

\section{Introduction:}

Control of anxiety in dentistry is one of the most important issues that dentists face in the clinic on a daily basis. ${ }^{(1,2)}$ Patient anxiety is one of the factors that affect the dentist's ease of work as well as the patient's peace of mind and his/her understanding of pain. Different methods have been used to reduce patient anxiety during treatment. ${ }^{(3)}$
One of the new techniques of reducing distress is to distract the patient's senses from the environment using various methods and techniques, including music, sound, and image. ${ }^{(4,5)}$

Distraction is based on the principle that each person has a limited attention capacity although when much of this focus is on another stimulus, it is unlikely that the stimulus is undesirable. ${ }^{(6)}$ 
Virtual reality (VR) technology creates a sense of immersion in a virtual environment analogous to the real world. VR has gained increasing attention for pain management based on current evidence demonstrating its analgesic effects in certain experimental acute and chronic pain conditions. ${ }^{(7,8)}$

VR-based interventions shift the users' attention towards active cognitive processing that can lead to higher pain threshold or tolerance and allow the user to interact with a simulated computer environment. ${ }^{(7,9,10)}$

The human brain can deal with a limited number of details; therefore, if the VR program is more complicated, it will be more effective in reducing pain. ${ }^{(11)}$

The results of studies on the use of VR in dental treatments are contradictory; ${ }^{(12-15)}$ in most studies, it has been recommended to use VR to reduce anxiety during treatment.

The purpose of this study was to investigate the effect of VR on working conditions and pain during scaling and root planing (SRP) in anxious patients.

\section{Materials and Methods}

In this clinical trial, 14 patients (the same sex distribution) with an average age of $31 \pm 7.4$ years participated. Informed consent was obtained from all the participants.

Inclusion Criteria:

-Patients who had anxiety during periodontal treatment according to the dental anxiety scale-revised (DAS-R) and had anxiety levels above $9 .^{(16)}$

-Patients requiring SRP in at least two equal quadrants simultaneously.

Exclusion Criteria:

-Patients with a history of psychological problems (based on the medical records).

-Smoking or use of special medications (tranquilizers).

The patients were randomly divided into two groups. We used a within-subject/split-mouth design to minimize the effects of confounding factors in each group. In the first group, SRP was done in the first quadrant according to the split- mouth design using eyeglasses (Carl Zeiss 1963, Germany) for distraction, while in the second group, SRP was done in the first quadrant without any intervention (control). It should be noted that a common film was used to reduce the patients' anxiety.

Next, in the second group, SRP was done in the second quadrant using eyeglasses for distraction, while in the first group, SRP was done in the second quadrant without any intervention (control).

These steps were performed with a two-week interval by a single researcher. The Patients' anxiety was measured using DAS-R index before SRP. A monitoring device (Cardioset SR110, Iran) was used to measure BP and PR before, during (three times every 3 to 5 minutes), and after SRP. The dental sedation teacher groups (DSTG) system and visual analog scale (VAS, pain during work) were used to measure the patients' anxiety during SRP. ${ }^{(17,18)}$

The patients' satisfaction with the treatment was assessed using a questionnaire about their pain and discomfort levels, and the responses were recorded in categories of good, moderate, and low.

Data were analyzed in SPSS 17 software (SPSS Inc., Chicago, IL, USA) using MannWhitney-U test.

\section{Results:}

The results of the DSTG index regarding the level of consciousness of the patients during work are shown in Table 1. The results showed a statistically significant difference in relaxation during SRP with and without the use of eyeglasses $(\mathrm{P}<0.001)$.

Table 1: Frequency distribution of relaxation status during work with the two methods

\begin{tabular}{lccc}
\hline & $\begin{array}{c}\text { With } \\
\text { eyeglasses }\end{array}$ & $\begin{array}{c}\text { Without } \\
\text { eyeglasses }\end{array}$ & P-value \\
\hline Fully relaxed & & & \\
& $14(50 \%)$ & $13(4.46 \%)$ & 0.0007 \\
\hline Drowsy & $0(0 \%)$ & $1(6.3 \%)$ & 0.08 \\
\hline Total & $14(50 \%)$ & $14(50 \%)$ & 0.0005 \\
\hline
\end{tabular}


The results of the DSTG index for working conditions with and without the use of eyeglasses are shown in Table 2. The results showed a significant difference between the two groups $(\mathrm{P}=0.001)$.

Table 2: Results of the dental sedation teacher groups (DSTG) index for working conditions with and without eyeglasses

\begin{tabular}{cccc}
\hline & $\begin{array}{c}\text { With } \\
\text { eyeglasses }\end{array}$ & $\begin{array}{c}\text { Without } \\
\text { eyeglasses }\end{array}$ & Total \\
\hline Good & $18(3.64 \%)$ & $0(0 \%)$ & $18(3.64 \%)$ \\
\hline Fair & $8(6.28 \%)$ & $0(0 \%)$ & $8(6.28 \%)$ \\
\hline Poor & $1(6.3 \%)$ & $1(6.3 \%)$ & $2(1.7 \%)$ \\
\hline Total & $27(4.96 \%)$ & $1(6.3 \%)$ & $28(10 \%)$ \\
\hline
\end{tabular}

The frequency distribution of the dentist's satisfaction is presented in Table 3. Significant differences were observed in the dentist's satisfaction with the two methods $(\mathrm{P}=0.001)$.

Table 3: Frequency distribution of the dentist's satisfaction with the two methods

\begin{tabular}{cccc}
\hline & With & Without & Total \\
& eyeglasses & eyeglasses & \\
\hline Good & $16(1.57 \%)$ & $0(0 \%)$ & $16(1.57 \%)$ \\
\hline Fair & $10(7.35 \%)$ & $1(6.3 \%)$ & $11(3.39 \%)$ \\
& & & \\
\hline Poor & $1(6.3 \%)$ & $0(0 \%)$ & $1(6.3 \%)$ \\
\hline Total & $27(4.96 \%)$ & $1(6.3 \%)$ & $28(100 \%)$ \\
\hline
\end{tabular}

The frequency distribution of the patients' satisfaction with the two methods is presented in Table 4. There was a significant difference in the patients' satisfaction with the two methods $(\mathrm{P}=0.001)$.
Table 4: Frequency distribution of the patients' satisfaction with the two methods

\begin{tabular}{cccc}
\hline & $\begin{array}{c}\text { With } \\
\text { eyeglasses }\end{array}$ & $\begin{array}{c}\text { Without } \\
\text { eyeglasses }\end{array}$ & Total \\
\hline Good & $6(4.21 \%)$ & $0(0 \%)$ & $6(4.21 \%)$ \\
\hline Fair & $21(75 \%)$ & $1(6.3 \%)$ & $22(6.78 \%)$ \\
\hline Total & $27(4.96 \%)$ & $1(6.35 \%)$ & $28(100 \%)$ \\
\hline
\end{tabular}

Comparison of the mean PR before, during, and after SRP with the two methods is shown in Table 5. There was a statistically significant difference between PRs during treatment with the two methods.

Table 5: Comparison of pulse rate (PR) before, during, and after work with the two methods

\begin{tabular}{lccccc}
\hline \multicolumn{1}{c}{ Pulse rate } & \multicolumn{2}{c}{ With } & \multicolumn{2}{c}{ Without } & P-value \\
& eyeglasses & eyeglasses & \\
& & & & & \\
& Mean & SD & Mean & SD & \\
\hline $\begin{array}{l}\text { Before } \\
\text { treatment }\end{array}$ & 28.85 & 29.11 & 53.84 & 55.15 & 0.676 \\
\hline $\begin{array}{l}\text { During } \\
\text { treatment }\end{array}$ & 43.89 & 43.12 & 71.81 & 60.12 & $<0.001$ \\
\hline After treatment & 28.83 & 54.11 & 42.81 & 72.12 & 0.452 \\
& & & & & \\
\hline
\end{tabular}


Table 6: Comparison of mean blood pressure (BP) before, during, and after work with the two methods

\begin{tabular}{|c|c|c|c|c|c|c|}
\hline \multirow{2}{*}{\multicolumn{2}{|c|}{ Blood pressure }} & \multicolumn{2}{|c|}{ With eyeglasses } & \multicolumn{2}{|c|}{ Without eyeglasses } & \multirow[t]{2}{*}{ P-value } \\
\hline & & Mean & $\mathrm{SD}$ & Mean & $\mathrm{SD}$ & \\
\hline \multirow{3}{*}{ Systolic } & $\begin{array}{l}\text { Before } \\
\text { treatment }\end{array}$ & 71.127 & 60.13 & 35.127 & 19.13 & 0.825 \\
\hline & $\begin{array}{l}\text { During } \\
\text { treatment }\end{array}$ & 61.136 & 77.14 & 82.126 & 39.14 & $<0.001$ \\
\hline & $\begin{array}{l}\text { After } \\
\text { treatment }\end{array}$ & 25.128 & 88.12 & 25.126 & 69.13 & 0.170 \\
\hline \multirow{3}{*}{ Diastolic } & $\begin{array}{l}\text { Before } \\
\text { treatment }\end{array}$ & 77 & 31.12 & 81.76 & 84.11 & 0.914 \\
\hline & $\begin{array}{l}\text { During } \\
\text { treatment }\end{array}$ & 85.81 & 79.15 & 82.76 & 62.12 & 0.026 \\
\hline & $\begin{array}{l}\text { After } \\
\text { treatment }\end{array}$ & 64.77 & 71.12 & 89.77 & 82.9 & 0.886 \\
\hline
\end{tabular}

$\mathrm{SD}=$ Standard Deviation

\section{Discussion:}

One of the main issues in dental care is the control of patient anxiety. Studies have shown that dental anxiety is associated with perceived pain related to different dental treatments. ${ }^{(19,20)}$ Anxiety results in avoidance behavior, which can only be discovered upon compulsory examinations; it is associated with higher rates of dental caries and needs for oral rehabilitation. ${ }^{(21,22)}$ As anxiety has a direct influence on oral health, it should be detected and accounted for in a treatment concept integrating dental and cognitive-behavioral therapeutic approaches. ${ }^{(22)}$

It has been demonstrated that higher dental anxiety is associated with poorer oral hygiene practices. ${ }^{(23)}$
Control of anxiety has a great impact on the quality of treatment. ${ }^{(24)}$ Conventional methods, such as premedication, use of anesthetics, etc., have some limitations and are not always accepted by patients.

VR is an interactive computer-generated experience taking place within a simulated environment. It mainly incorporates auditory and visual feedback but may also allow other types of sensory feedback such as haptic.

This immersive environment can be similar to the real world or it can be fantastical. Augmented reality systems may also be considered a form of VR that layers virtual information over a live camera feed into a headset or through a smartphone or tablet device, giving the user the ability 
to view three-dimensional (3D) images. ${ }^{(25)}$ It offers several advantages, including a more realistic lifelike environment that may allow subjects to forget that they are being assessed, allowing better participation and an increased generalization of learning. Moreover, the VR system can provide multimodal stimuli, such as visual and auditory stimuli, can be used to assess the patient/s multimodal integration, and can be used to rehabilitate cognitive abilities. The use of VR to treat various psychiatric disorders in adults (phobic anxiety disorders, post-traumatic stress disorder (PTSD), eating disorders, addiction, etc.) and its efficacy are supported by numerous studies. ${ }^{(26)}$

To date, few theories have been proposed regarding the pain-attenuating effects of VR beyond simple distraction. To understand the underlying mechanism of VR analgesia, researchers have considered the neurobiological interplay of brain cortices and neurochemistry, as well as emotional, cognitive, and attentional processes. (26) Melzack and Wall proposed the gate control theory of pain, which suggests that factors such as the level of attention paid to the pain, the emotion associated with the pain, and past experience of the pain, all play a role in how the pain will be interpreted. ${ }^{(27)}$ Gold et al hypothesized that VR analgesia originates from intercortical modulation among signaling pathways of the pain matrix through attention, emotion, memory and other senses, thereby inducing analgesia. ${ }^{(28)}$ In general, VR has been demonstrated to be effective in increasing pain tolerance and threshold, as well as decreasing pain intensity, affective distress, and unpleasantness of pain ${ }^{(29,30)}$

Approximately, two-thirds of the study population reported that they preferred the VR distraction method during SRP; one-third preferred to watch the movie, and only one patient preferred no distraction. Not only did the patients prefer interacting with the VR environment and reported lower levels of pain, but they also had significantly lower PR and BP measurements during the VR experience $^{(31)}$

In this study, video eyeglasses were used to distract the patients during SRP to reduce anxiety and facilitate the procedure. According to the results of the present study, VAS index was significantly different between the two groups (with and without eyeglasses); this index was significantly lower when the eyeglasses were being used $(\mathrm{P}<0.05)$. These data show that patients experience less pain when using these eyeglasses during SRP.

These results are in line with studies that have shown a significant decrease in pain perception and anxiety scores with the use of VR eyeglasses during dental treatments. ${ }^{(31-37)} \mathrm{A}$ systematic review indicated the effectiveness of VR in conjunction with pharmacologic analgesia in reducing pain and anxiety in burn injury patients undergoing wound dressing changes and physiotherapy management compared with pharmacologic analgesia alone or other forms of distraction. ${ }^{(38)}$ Overall, controlled research suggests that VR distraction may be a useful tool for clinicians who work with a variety of pain problems. ${ }^{(39)}$

The DSTG index on the patient/s relaxation status during work showed that there is a significant difference between the work with and without eyeglasses, and patients feel more comfortable while wearing eyeglasses during work. This result is consistent with the results found by Kozarek et al who examined the effect of video eyeglasses on patients during gastrointestinal (GI) examinations. ${ }^{(40)}$ It is also in line with the results reported by Padrino-Barrios et al who support the use of VR eyewear as an effective technique of reducing anxiety in adults during oral debridement. ${ }^{(41)}$ A meta-analysis revealed large declines in anxiety symptoms with VR. ${ }^{(42)}$

A study on children showed that audiovisual eyeglasses are an effective distraction tool for the alleviation of the unpleasantness of pain and distress that arise during dental restorative procedures. $^{(43)}$

In addition, in the second phase of the DSTG test, it was shown that working conditions during the use of eyeglasses were good in most cases $(96 \%)$, while during work without eyeglasses, this rate was $64 \%$.

In this study, the patients' and dentist>s satisfaction levels were higher when working with eyeglasses, which would be very effective in the quality of treatment. We detected a significant reduction in the patients' PR during treatment with the use of eyeglasses.

\section{Conclusion:}

Overall, the results of the present study indicated 
that video eyeglasses can be a useful tool for dentists to improve the quality of dental treatments through increasing the patients' and the dentist's satisfaction and reducing the patients' pain experience and anxiety.

\section{References:}

1.Arane K, Behboudi A, Goldman RD. Virtual reality for pain and anxiety management in children. Can Fam Physician. 2017 Dec;63(12):93234.

2.Bradt J, Teague A. Music interventions for dental anxiety. Oral Dis. 2018;24(3):300-6.

3.Maulina T, Djustiana N, Shahib MN. The Effect of Music Intervention on Dental Anxiety During Dental Extraction Procedure. Open Dent J. 2017;11:565-72.

4. Zhang C, Qin D, Shen L, Ji P, Wang J. Does audiovisual distraction reduce dental anxiety in children under local anesthesia? A systematic review and meta-analysis. Oral Dis. 2019 Mar;25(2):416-24.

5. Burghardt S, Koranyi S, Magnucki G, Strauss B, Rosendahl J. Non-pharmacological interventions for reducing mental distress in patients undergoing dental procedures: Systematic review and meta-analysis. J Dent. 2018;69:22-31.

6. Hoffman HG, Patterson DR, Carrougher GJ. Use of virtual reality for adjunctive treatment of adult burn pain during physical therapy: a controlled study. Clin J Pain. 2000;16(3):244-50.

7. Gazerani P. Virtual Reality for Pain Control Virtual or Real? US Neurol. 2016;12(2):82-3.

8. Singh D, Samadi F, Jaiswal J, Tripathi AM. Stress Reduction through Audio Distraction in Anxious Pediatric Dental Patients: An Adjunctive Clinical Study. Int J Clin Pediatr Dent. 2014;7(3):149-52.

9. Hoffman HG, Patterson DR, Carrougher GJ, Nakamura D, Moore M, Garcia-Palacios A, et al. The Effectiveness of Virtual Reality Pain Control With Multiple Treatments of Longer Durations: A Case Study. Int J Hum Comput Interact. 2001;13(1):1-12.

10.Hoffman HG, Patterson DR, Magula J, Carrougher GJ, Zeltzer K, Dagadakis S, et al. Waterfriendly virtual reality pain control during wound care. J Clin Psychol. 2004;60(2):189-95.

11.Zimmer P, Buttlar B, Halbeisen G, Walther $\mathrm{E}$, Domes G. Virtually stressed? A refined virtual reality adaptation of the Trier Social Stress Test
(TSST) induces robust endocrine responses. Psychoneuroendocrinology. 2019 Mar;101:186-92.

12.Hoffman HG, Garcia-Palacios A, Patterson DR, Jensen M, Furness T 3rd, Ammons WF Jr. The effectiveness of virtual reality for dental pain control: a case study. Cyberpsychol Behav. 2001 Aug;4(4):527-35.

13.Hoffman HG, Doctor JN, Patterson DR, Carrougher GJ, Furness TA 3rd. Virtual reality as an adjunctive pain control during burn wound care in adolescent patients. Pain. 2000;85(1-2):305-9. 14. Triberti S, Repetto C, Riva G. Psychological Factors Influencing the Effectiveness of Virtual Reality-Based Analgesia: A Systematic Review. Cyberpsychol Behav Soc Netw. 2014 Jun;17(6):335-45.

15.Prabhakar AR, Marwah N, Raju OS. A comparison between audio and audiovisual distraction techniques in managing anxious pediatric dental patients. J Indian Soc of Pedod Prev Dent. 2007;25(4):177-82.

16. Ronis DL, Hansen CH, Antonakos CL. Equivalence of the original and revised dental anxiety scales. J Dent Hyg. 1995;69(6):270-2.

17.Berghmans JM, Poley MJ, van der Ende J, Weber F, Van de Velde M, Adriaenssens P, et al. A Visual Analog Scale to assess anxiety in children during anesthesia induction (VAS-I): Results supporting its validity in a sample of day care surgery patients. Paediatr Anaesth. 2017;27(9):955-61.

18. Choi SC, Yang Y, Yoo S, Kim J, Jeong T, Shin TJ. Development of a Web-Based Nationwide Korean Pediatric Dental Sedation Registry. J Clin Pediatr Dent. 2017;41(6):478-81.

19. Hakeberg M, Cunha L. Dental anxiety and pain related to dental hygienist treatment. Acta Odontol Scand. 2008;66(6):374-9.

20.Huang D, Wun E, Stern A. Current treatments and advances in pain and anxiety management. Dent Clin North Am. 2011 Jul;55(3):609-18, x.

21.Guzeldemir E, Toygar HU, Cilasun U. Pain perception and anxiety during scaling in periodontally healthy subjects. J Periodontol. 2008;79(12):2247-55.

22. Eitner S, Wichmann M, Paulsen A, Holst S. Dental anxiety--an epidemiological study on its clinical correlation and effects on oral health. $\mathrm{J}$ Oral Rehabil. 2006;33(8):588-93.

23.DeDonno MA. Dental anxiety, dental visits and oral hygiene practices. Oral Health Prev Dent. 2012;10(2):129-33. 
24.Goulart JCF, Pinheiro MD, Rodrigues RV, Santos FdSAd, Martins AT, Scannavino FLF. Influence of anxiety on blood pressure and heart rate during dental treatment. J Revista Odonto Ciência. 2012;27:31-5.

25.Dunn J, Yeo E, Moghaddampour P, Chau B, Humbert S. Virtual and augmented reality in the treatment of phantom limb pain: A literature review. NeuroRehabilitation. 2017;40(4):595601.

26.Bioulac S, de Sevin E, Sagaspe P, Claret A, Philip P, Micoulaud-Franchi JA, et al. [What do virtual reality tools bring to child and adolescent psychiatry?]. Encephale. 2018 Jun;44(3):280-5. 27. Melzack R, Wall PD. Pain mechanisms: a new theory. Science. 1965 Nov 19;150(3699):971-9. 28. Gold JI, Belmont KA, Thomas DA. The neurobiology of virtual reality pain attenuation. $\mathrm{Cy}$ berpsychol Behav. 2007 Aug;10(4):536-44.

29.Rutter CE, Dahlquist LM, Weiss KE. Sustained efficacy of virtual reality distraction. J Pain. 2009 Apr; 10(4): 391-7.

30.Dahlquist LM, Weiss KE, Clendaniel LD, Law EF, Ackerman CS, McKenna KD. Effects of videogame distraction using a virtual reality type head-mounted display helmet on cold pressor pain in children. J Pediatric Psychol. 2009;34(5):574-84.

31.Furman E, Jasinevicius TR, Bissada NF, Victoroff KZ, Skillicorn R, Buchner M. Virtual reality distraction for pain control during periodontal scaling and root planing procedures. J Am Dent Assoc. 2009;140(12):1508-16.

32.Frere CL, Crout R, Yorty J, McNeil DW. Effects of audiovisual distraction during dental prophylaxis. J Am Dent Assoc. 2001;132(7):1031-8.

33.Asl Aminabadi N, Erfanparast L, Sohrabi A, Ghertasi Oskouei S, Naghili A. The Impact of Virtual Reality Distraction on Pain and Anxiety during Dental Treatment in 4-6 Year-Old Children: a Randomized Controlled Clinical Trial. J Dent Res Dent Clin Dent Prospects. 2012;6(4):117-24.

34.Indovina P, Barone D, Gallo L, Chirico A, De Pietro G, Giordano A. Virtual Reality as a Distraction Intervention to Relieve Pain and Distress During Medical Procedures: A Comprehensive Literature Review. Clin J Pain. 2018 Sep;34(9):858-77.

35.Niharika P, Reddy NV, Srujana P, Srikanth K,
Daneswari V, Geetha KS. Effects of distraction using virtual reality technology on pain perception and anxiety levels in children during pulp therapy of primary molars. J Indian Soc Pedod Prev Dent. 2018;36(4):364-9.

36. Wismeijer AA, Vingerhoets AJ. The use of virtual reality and audiovisual eyeglass systems as adjunct analgesic techniques: A review of the literature. Ann Behav Med. 2005 Dec;30(3):26878.

37. Shariatmadarahmadi R, Avadi MR, Dastani A. Evaluating the Effect of EMLA Anesthetic Gel on the Level of Pain upon Probing in Patients with Chronic Periodontitis. J Res Dentomaxillofac Sci. 2016;1(4):26-31.

38. Morris L, Louw Q, Grimmer-Somers K. The Effectiveness of Virtual Reality on Reducing Pain and Anxiety in Burn Injury Patients A Systematic Review. Clin J Pain. 2009 NovDec;25(9):815-26.

39. Malloy KM, Milling LS. The effectiveness of virtual reality distraction for pain reduction: A systematic review. Clin Psychol Rev. 2010 Dec;30(8):1011-8.

40.Kozarek RA, Raltz SL, Neal L, Wilbur P, Stewart S, Ragsdale J. Prospective trial using Virtual Vision as distraction technique in patients undergoing gastric laboratory procedures. Gastroenterol Nurs. 1997 Jan-Feb;20(1):12-4.

41.Padrino-Barrios C, McCombs G, Diawara N, De Leo G. The Use of Immersive Visualization for the Control of Dental Anxiety During Oral Debridement. J Dent Hyg. 2015;89(6):372-7.

42.Parsons TD, Rizzo AA. Affective outcomes of virtual reality exposure therapy for anxiety and specific phobias: a meta-analysis. J Behav Ther Exp Psychiatry. 2008 Sep;39(3):250-61.

43. Ram D, Shapira J, Holan G, Magora F, Cohen S, Davidovich E. Audiovisual video eyeglass distraction during dental treatment in children. Quintessence Int. 2010 Sep;41(8):673-9.

Please cite this paper as:

Birang E, Yaghini J, Birang R, Zohary M. Effect of Virtual Reality During Periodontal Treatment of Patients with Anxiety . J Res Dentomaxillofac Sci. 2019; 4 (1):7-13. 